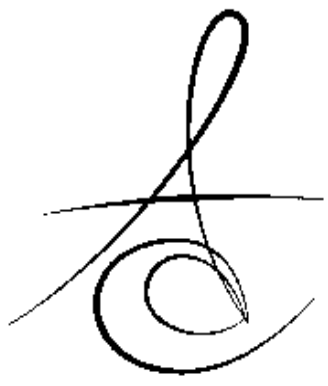

\section{HAREKETLİ PROTEZ KULLANIMI İLE İLİŞKİLİ ORAL MUKOZA LEZYONLARI VE RİSK FAKTÖRLERİ}

\author{
REMOVABLE DENTURE-RELATED ORAL MUCOSAL LESIONS AND RISK \\ FACTORS
}

Dr. Öğr. Üyesi Nursel AKKAYA*

Prof. Dr. Sema DURAL*
Makale Kodu/Article code: 3196
Makale Gönderilme tarihi: 13.12 .2016
Kabul Tarihi: 08.02.2017

\section{öz}

Hareketli protez kullanımı ile ilişkili oral mukoza lezyonlarına protez kullanan hastaların yaklaşık \%50'sinde rastlanmaktadır. Bu lezyonlardan bazıları enfeksiyöz orijinlidir. Çeşitli lokal ve sistemik risk faktörleri bu lezyonların gelişimine katkıda bulunabilmektedir. Risk faktörleri; hatalı ya da doku uyumu bozuk protezlerin oral mukozada yol açtığı travmatik yaralanma, kötü ağız ve protez hijyeni, protezlerin devamlı kullanılması, protezlerin uzun yıllar kullanılmasını içerir. İlaç tedavileri, sistemik hastalıklar ve beslenme bozuklukları gibi diğer risk faktörleri de lezyonların gelişimini ve şiddetini etkileyebilir. Yaşlı hastalar bu lezyonların ortaya çıkmasına daha yatkındırlar. Lezyonlar genellikle asemptomatik olduğu için, intraoral muayene sırasında tesadüfi bir bulgu olarak saptanır.

Hareketli protez kullanımına bağlı oral mukoza lezyonları; protez stomatiti, angular şelitis, mesnetsiz kret, epulis fissuratum, fibroepitelyal polip, travmatik ülser, travmatik fibrom, friksiyonel keratozis ve oral karsinomdur. Protezlerin oral mukozada oluşturduğu kronik travmanın mukozayı oral ve orofaringeal karsinom gelişimine yatkın hale getirebildiğine dair kanıtlar vardır. Bu lezyonların önlenmesi için hastaların protezlerin hijyeninin önemi, protez kullanımına ilişkin önerilere uyulması konularında bilgilendirilmeleri gereklidir. Protez kullanan hastalar oral mukoza lezyonları ve protezlerin değerlendirilmesi için düzenli olarak kontrollere çağırılmalıdırlar.

Anahtar Kelimeler: Hareketli protez, Oral mukoza lezyonları, Protez stomatiti, Travmatik ülser, Oral karsinoma

\section{ABSTRACT}

Removable denture-related oral mucosal lesions are encountered in almost half of the denture wearers. Some of these lesions have an infectious origin. Several local and systemic risk factors may contribute to development of the lesions. Predisposing factors include chronic traumatic injury of oral mucosa caused by defective or ill-fitting dentures, poor oral and denture hygiene, continual wearing of dentures, increasing age of the denture. Other risk factors such as medications, systemic diseases, malnutrition may also effect the development and severity of the lesions. Elderly patients are more prone to occurrence of these lesions. Since the lesions are usually asymptomatic, they are discovered as an incidental finding in intraoral examination.

Removable denture-related oral mucosal lesions include denture stomatitis, angular cheilitis, flabby ridge, epulis fissuratum, fibroepithelial polyp, traumatic ulcers, traumatic fibroma, frictional keratosis and oral carcinoma. There are evidences that chronic trauma of the oral mucosa by dentures may predispose mucosa to the development of oral and oropharenyngeal carcinomas. In order to prevent of these lesions, patients should be informed about the importance of denture hygiene and to follow the instructions related to denture usage. Denture wearers should be recalled regularly for the evaluation of oral mucosal lesions and dentures.

Key Words: Removable denture, Oral mucosal lesions, Denture stomatitis, Traumatic ulcer, Oral carcinoma

*Hacettepe Üniversitesi, Diş Hekimliği Fakültesi, Ağız, Diş ve Çene Radyolojisi Anabilim Dalı, Ankara 
Atatürk Üniv. Diş Hek. Fak. Derg.

J Dent Fac Atatürk Uni

Cilt:29, Sayı:4, Yıl: 2019, Sayfa: 667-675

\section{GİRIŞ̧}

Kısmi ya da tam diş eksikliklerinin fonksiyonel ve estetik rehabilitasyonu için konvansiyonel hareketli protezler (HP) sıklıkla tercih edilen bir tedavi seçeneğidir. ${ }^{1} \mathrm{HP}$ ağız sağlığı ile ilişkili yaşam kalitesini artırmakta, ancak tedaviden 1-5 yıl sonra protezlerde doku uyumu sorunları ve oral mukozada inflamasyon gelişebilmektedir. ${ }^{2}$ Protezlerin kullanım süresi çeşitli çalışmalarda 5-10 yıl olarak bildirilmiş olmasına karşın, ${ }^{2-4}$ yaşlı hastaların \%35'inin protezlerini 30 yıldan fazla kullandığı belirlenmiştir. ${ }^{5}$ Araştırmalar özellikle yaşlı hastaların \%50'sinin doku uyumu bozuk, ${ }^{6}$ yaklaşık $\% 80$ 'inin hijyenin yeterince sağlanamadığı protezleri kullanmakta olduklarını göstermiştir. ${ }^{5}$ Protezlerin doku uyumunun bozulması, uzun yıllar kullanılması ve kötü hijyen oral mukoza lezyonlarının gelişmesinde doğrudan etkili risk faktörleri olarak tanımlanmıştır. ${ }^{6}$ Protezlerin mukozada oluşturduğu travma, protez kullanım önerilerine uyulmaması gibi lokal etkenlerle birlikte, bazı sistemik durumlar da hazırlayıcı risk faktörü olarak rol oynar. ${ }^{5-7}$

Protezlerin başarı oranı uygun şekilde tasarlanmalarının yanı sıra, hasta takibine de bağlıdır. ${ }^{8}$ HP kullanan hastaların \%50-54'ünde hareketli proteze bağlı oral mukoza lezyonları görüldüğü bildirilmiştir. ${ }^{6,9-}$ 12 Görülme sıklığının yaşla birlikte artış göstermesi ve total protez kullanan hastalarda daha fazla rastlanması nedeniyle, ${ }^{10,11}$ yaşılıarda oral mukozanın düzenli olarak kontrolü önerilmektedir.8,13,14 Bununla birlikte, toplumda total protez kullanan hastaların kontrol gereksinimi olmadığına dair yaygın bir inanış vardır. ${ }^{5}$ Ayrıca yaşlı hastaların ağız sağlığını önemli görmedikleri, kontrole gitme ve protezlerini yeniletme konusunda isteksiz oldukları, bu durumun gelişmesinde ekonomik sıkıntıların da rol oynadığı ifade edilmiştir. ${ }^{15}$ Hekimler açısından bakıldığında ise, protezlerin amacının estetik ve rehabilitasyon odaklı olduğu, hastaların protezlerin bakımı, kullanımı, oral hijyenin korunması konularında eğitilmesinin başarıdaki öneminin göz ardı edildiği görülmektedir. $^{8}$

HP'nin kullanımı ile ilişkili lezyonlar; protez stomatiti, angular şelitis, mesnetsiz kret, epulis fissuratum, fibroepitelyal polip, travmatik ülser, travmatik fibrom, friksiyonel keratozis ve oral karsinomdur.

\section{Protez Stomatiti}

Protez stomatiti, protezin kapladığı mukozanın inflamatuar reaksiyonudur. HP kullanan hastalarda en sık görülen oral mukoza lezyonudur. Ortodontik aparey
AKKAYA, ÇAĞIRANKAYA, DURAL

ve obtüratör kullanımı ile de ortaya çıkabilmektedir. ${ }^{16}$ Epidemiyolojik çalışmalarda prevalansı \%15-70 arasında bildirilmiştir. ${ }^{17}$

Etiyolojisi çok etmenlidir. Çalışmalar yaşııık, cinsiyetin kadın olması, ${ }^{16,18}$ tütün kullanımı, ${ }^{19-22}$ eğitim seviyesinin düşük olması ${ }^{22}$ ve düzenli diş kontrolüne gitmemenin ${ }^{23}$ protez stomatitinin etiyolojisinde rol oynadığını göstermektedir. Protezlerle ilişkili olarak; hatalı ve doku uyumu bozuk protezlerin oluşturduğu mukozal travma, ${ }^{24}$ geceleri protezlerin çıkarılmaması, ${ }^{19,21}$ protezlerin hijyeninin yetersiz olması, ${ }^{25}$ protezlerin uzun yıllar kullanılması, ${ }^{6}$ total protez kullanımı ${ }^{13,21}$ ve maksiller protez kullanımı ${ }^{26}$ protez stomatitine yatkın hale getiren faktörlerdir. $\mathrm{Bu}$ faktörlerin yanı sıra sistemik durum da oral mukozada stomatit gelişimi için uygun ortam oluşumuna katkıda bulunur. ${ }^{27-29}$

Bununla birlikte başlıca etiyolojik faktör mikrobiyaldir. Candida albicans başta olmak üzere $C$. glabrata, C. tropicalis ve diğer candida türleri ile gram negatif anaerob mikroorganizmaların etken olduğu saptanmıştır. ${ }^{19,30-32}$ Candida albicans ve alt türleri hastalığın başlamasında, devam etmesinde ve şiddetlenmesinde majör rol oynar. ${ }^{16,33}$ Candida albicans'ın tek başına ya da diğer Candida türleri ile birlikte protezde kolonizasyonu gösterilmiştir. ${ }^{30}$

\section{Etiyolojik faktörler}

\section{I.i. Candida enfeksiyonu}

Sık rastlanan mikroorganizmalar olarak Candida türleri asemptomatik bireylerde de oral kavitede bulunabilen fırsatçı patojenlerdir. Sağlıklı bireylerde ve normal ağız ortamında enfeksiyon oluşturmaları konağın bağışıklık sistemince engellenir. Bu mikroorganizma türü epitele bağlanma, epitelyal bütünlüğü bozma ve invazyon oluşturma kapasitesine sahiptir. ${ }^{34-36}$ Protezlerin geceleri çıkarılmaması tükürüğün yararlı etkilerini engeller. Tükürük bileşenleri ve dil konağın savunma sisteminin bir parçasıdır. Protez altındaki dokunun izolasyonu, dokunun kendi mikroçevresini oluşturmasına yol açarak, normal mikrobiyolojik dengenin lokal olarak bozulmasına yol açar. ${ }^{20,37}$

Dorocka-Bobkowska ve ark $^{33}$ protez stomatitine tek başına candida enfeksiyonunun neden olmadığını, doku uyumu bozuk protezlerin oluşturduğu doku travmasına bağlı inflamasyonla mikroorganizmalar için uygun bir çevre oluştuğunu diğer etiyolojik faktörlerin de duruma katkı sağladığını ifade etmişlerdir.

\section{I.ii. Demografik ve sistemik faktörler}

Protez stomatitinin yaşlılarda daha sık görüldüğü çeşitli çalışmalarda belirtilmiştir. ${ }^{10,23,38}$ Figueiral

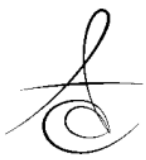


ve ark. ${ }^{39}$ ise yaşlıların ve alkol tüketimi yüksek bireylerin protez stomatitine daha az duyarlı olduğunu bulmuşlardır. Baran ve Nalçacı ${ }^{22} 70$ yaş üstünde protez stomatitinin sıklığının azaldığını bildirmişlerdir. Bu sonuçlar azalmış tükürük akışı gibi protez kullanmayı güçleştiren durumlara bağlı olarak protezlerin bu yaş grubunda düzenli kullanılamamasına bağlı olabilir. Bir başka çalışmada Candida ile ilişkili protez stomatitinin nötrofil fonksiyon yetersizliği ile ilişkili olduğu ve yaşlanmanın bu hücrelerin fagositoz ve öldürme gibi önemli özelliklerinde şiddetli disfonksiyona yol açarak, bu enfeksiyonun gelişimini kolaylaştırdığı bildirilmiştir. ${ }^{40}$

Pek çok çalışmada kadınlarda daha sık rastlan-

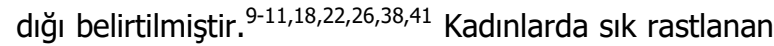
bir lezyon olması estetik kaygı nedeniyle protezlerini devamlı kullanmalarına bağlanmaktadır. ${ }^{9}$ Ayrıca hormonal faktörlerin de ağız ortamının protez stomatiti gelişimine yatkın hale gelmesinde rol oynayabileceği düşünülmektedir. Menapozun oral mukozada değişikliklere ve tükürük akışında azalmaya yol açtığı bildirilmiştir.42,43 Tükürük bezi fonksiyon bozukluğu ${ }^{44}$ ve tükürük sekresyon hızı ${ }^{20}$ protez stomatiti ile ilişkili bulunmuştur. Dağıstan ve ark. $^{32}$ ise protez stomatiti sıklığını erkeklerde yüksek bulmuş ve bu sonucu protezlerin hijyen yetersizliği ile açıklamışlardır.

Eğitim düzeyi arttıkça protez stomatiti görülme oranı azalmaktadır. ${ }^{22,23}$ Bu sonuç eğitim düzeyinin artması ile birlikte oral hijyen durumunun iyileşmesi ile ilişkilendirilebilir.

Diabetes mellitus, ${ }^{45-48}$ antibiyotik tedavisi, ${ }^{49}$ immün yetmezlik, ${ }^{27,49}$ A vitamini eksikliği, ${ }^{21}$ folat $^{50}$ ve demir eksikliği ${ }^{51}$ sistemik olarak protez stomatiti oluşumuna yatkın hale getiren durumlardır. Diabetes mellituslu bireylerde protez stomatitinin hem sıklığının hem de şiddetinin daha fazla olduğu belirlenmiştir. ${ }^{52}$ Diabetik hastalarda hiposalivasyon ve tükürüğün bileşimdeki değişiklikler, candida ile ilişkili protez stomatitine duyarlılığı artırır. ${ }^{46}$

\section{I.iii. Protezler ile ilgili faktörler}

Protezlerin hijyeninin yetersiz olması kesin bir etiyolojik faktör olarak belirlenmiştir. ${ }^{22,26,53}$ Shulman ve ark. ${ }^{21}$ candida etken olsa da her hastada enfeksiyon oluşturmaması nedeniyle protezlerin temizliği, gece çıkarılması ve A vitamininden zengin diyetin önemli olduğunu vurgulamışlardır. Yaşlı hastaların sadece \%28'inin protezlerin günlük temizliğini yaptığı belirlenmiştir. ${ }^{54}$ Çalışmalar hastaların büyük bir kısmının protezleri sadece fırçalayarak temizlediklerini göstermek- tedir. ${ }^{22,55,56}$ Sadece fırça ile yapılan temizlik, protezlerin hijyeninin sağlanmasında yetersiz kalmaktadır. İyi temizlenmeyen protezlerin yüzeyinde hızla oluşan bakteri ve mantarları içeren biyofilm ve plak nedeniyle oral mukozada inflamasyon gelişmektedir. ${ }^{57} \mathrm{Bu}$ nedenle hastalara mekanik temizliğe ek olarak dezenfektan solüsyon kullanmaları önerilmelidir.

Protezlerin gece çıkarılmamasının protez stomatiti gelişiminde en önemli risk faktörü olduğu düşünülmektedir. ${ }^{7,19,22,36,37,54,55,57,58}$ Protezlerin devamlı ağızda olması kaide materyali ve oral mukoza arasında fırsatçı enfeksiyon gelişimi için uygun bir ortam yaratır. Geçmişte protez materyaline alerjik cevap protez stomatiti gelişimine katkıda bulunan önemli bir faktör olarak düşünülürken, ${ }^{25}$ modern protez materyallerinin kullanılmasıyla bu durumun ortadan kalktığı ifade edilmiştir. $^{17}$

Protezin uzun yıllar kullanılması doku uyumunun bozulmasına yol açarak, protez stomatiti gelişimine uygun bir ortam yaratır. 7,36,38

İmplant destekli hareketli protezler ile konvansiyonel HP'nin karşılaştırıldığı bir çalışmada iki grup arasında protezlerin hijyeni bakımından bir fark olmamasına karşın, konvansiyonel HP kullanan hastalarda protez stomatiti gelişme riskinin daha fazla olduğu ve etiyolojide travmanın önemli rol oynadığı saptanmıştır. ${ }^{37}$ $\mathrm{Bu}$ nedenle protezin stabilitesinin artması stomatit riskinin azalmasında etkili bir faktör gibi görünmektedir.

\section{Klinik Bulgular}

Protez stomatiti maksillada mandibulaya göre daha fazla görülür. Sık rastlanan bir lezyon olmasına karşın, çoğunlukla asemptomatik olduğu için hastalar bu durumun farkında değildir. ${ }^{59}$ Nadiren mukozada kanama, ağrı, kaşıntı hissi, yanma, halitozis, tat bozukluğu ve ağız kuruluğu şikâyeti mevcuttur. ${ }^{16,46}$ Protez stomatiti angular şelitis, atrofik glossit, akut psödomembranöz kandidiyazis, kronik hiperplastik kandidiyazis ile ilişkilidir. ${ }^{16}$

Protez stomatiti protez altındaki inflamasyonlu mukozanın klinik görünümüne göre üç tip olmak üzere sınıflandıııır. Çeşitli sınıflandırmalar bulunmakla birlikte araştırmalarda sıklıkla kullanılan Newton sınıflandırmasına göre; sınırlı noktasal hiperemi alanları şeklinde tanımlanan Tip 1 başlangıç aşamasını ifade ederken, palatal mukozada protezin kapladığı alanların yaygın eritem ve ödemi olarak tanımlanan Tip 2 en yaygın görülen formdur. Etkilenen alan protezin sınırlarını net bir şekilde gösterir (Şekil. 1). Ağrılı olmayan bu durum angular şelitisle ilişkili olabilmektedir. Bu aşamada

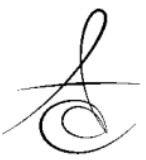


tedavi edilmezse uzun dönemde sıklıkla atrofik alanlarla ilişkili damağın santral kısmında nodüler lezyon gelişimi ile sonuçlanan hiperplastik reaksiyon olarak tanımlanan ve papiller hiperplazi olarak adlandırılan Tip 3'e dönüşebileceği ifade edilmektedir. ${ }^{16}$

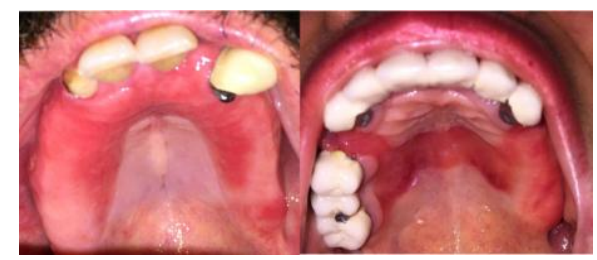

Şekil. 1. Hareketli bölümlü protez kullanan iki farklı hastada tip 2 protez stomatiti.

\section{Tedavi}

Protezlerin temizliğinin sağlanması ile oral hijyenin iyileştirilmesi, protezin örttüğü dokuların istirahat periyodunun artırılması, endikasyonu varsa antifungal tedavi, doku uyumu bozuk protezlerin oluşturduğu travmanın ortadan kaldırımasıdır. Antifungal tedavinin tek başına uygulanması önerilmez. Çünkü candida albicans enfeksiyonu hijyen düzeltilmezse ve protezlerdeki sorunlar giderilmezse tekrar eder. ${ }^{59,60}$ Granüler tip protez stomatitinde papiller hiperplazinin cerrahi eliminasyonu optimal mukoza hijyenine ulaşmak için gerekli olabilir. Ancak hafif şiddetteki olgularda cerrahi olmaksızın antifungal tedavi uygulanabilir. ${ }^{61}$ Altarawneh ve ark. $^{62}$ protezlerin candida türü organizmalar için rezervuar oluşturduğunu, bu nedenle antifungal tedaviden çok mevcut protezlerin sanitizasyonu ya da yeni protezlerin yapılmasının yararlı olacağını vurgulamışlardır.

\section{Angular Şelitis}

\section{Etiyoloji ve Klinik Görünüm}

Angular şelitis komissural vermillion alanlarının inflamasyonu olup, genellikle bilateral parlak kırmızı, eritemli fissürler şeklinde görülür (Şekil.2). Genellikle Candida albicans'ın etken olduğu bir durumdur. Staphylococcus aureus ve/veya $\beta$-hemolytic streptococci enfeksiyonu olarak da gelişebilir. ${ }^{63}$ Sıklıkla protez stomatitine eşlik eder. ${ }^{27,64,65}$ Gelişiminde hem lokal hem de sistemik faktörler etkilidir. ${ }^{66}$ Erkeklerde daha yüksek prevalansta görüldüğü bildirilmiştir., ${ }^{9,24}$ Düşük okluzal vertikal boyut, yetersiz maksiller dudak desteği, uyumsuz ve patojenik protezler, ${ }^{15,63}$ yaş, tam dişsizlik, ağızda Candida varlığı angular şelitisle ilişkili bulunmuştur. ${ }^{12,64}$ Protezin kullanım süresi arttıkça angular şelitis frekansında da artış görmüştür. ${ }^{9}$ Vertikal boyutun azalması ağız köşelerinde yumuşak doku katlantısı oluşmasına ve bu bölgelerde tükürüğün birikmesine yol açar. Tükürükteki enzimlerin doku ile uzun süreli teması irritasyona yol açarak lokal inflamasyon oluşturur. ${ }^{64}$ Yaşlılılarda \%11 olan görülme sıklığı protez kullanımı ile \%18'e yükselir. ${ }^{63}$ Süresi birkaç günden aylara hatta yıllara değişir. Alerjik reaksiyon olarak da ortaya çıkabilir. Nikel alerjisi olan bireylerde nikel içeren protezler ya da ortodontik braketlere bağlı olarak ortaya çıkabilmektedir. Diş macunu, gargara, diş ipi ve kozmetik ürünlere bağlı alerjik reaksiyonlar angular şelitis şeklinde gelişebilmektedir. Ayrıca uzun süre UV ışığa maruz kalma, tütün kullanımı, kserostomi de etken olarak kabul edilmektedir. Kserostomi tükürük bezlerine ait lokal nedenlerin yanı sıra, yaşlanma, diabetes mellitus, radyoterapi ve ilaç yan etkilerine bağlı olarak da gelişebilir. ${ }^{63-66}$

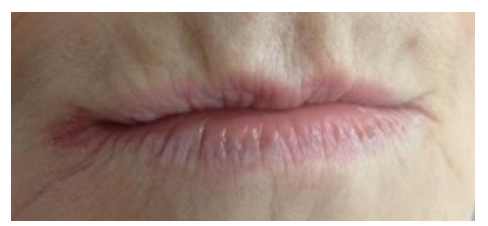

Şekil. 2. Total protez kullanan bir hastada bilateral, eritematöz angular şelitis lezyonları.

Beslenme yetersizliğine bağlı B vitamini eksikliği ve anemi, immün disfonksiyon gibi sistemik faktörlerin lokal faktörlerden daha önemli olduğu görülmüştür. ${ }^{59,65}$ Demir, $B_{2}, B_{6}, B_{12}$, folik asit, niyasin ve çinko eksikliğinin klinik bulgusu olarak gelişir. ${ }^{66} \mathrm{Bu}$ nedenle alkoliklerde, B vitamini metabolizmasını etkileyen ilaçlar kullananlarda, pernisiyöz anemide, gastrointestinal hastalıklarda (sıklıkla Crohn hastalığında), vegan diyeti yapanlarda ve sıklıkla HIV pozitif bireylerde görülebilmektedir. ${ }^{16,65,66}$

Hareketli protez kullanan Tip 2 diabetes mellituslu hastalarda angular şelitis, sağlıklı kontrol grubuna göre daha sık görülmüştür. Bu hastalarda enfeksiyonun protezin kapladığı oral mukozadan ağız köşelerine yayılarak geliştiği düşünülmektedir. ${ }^{33}$

Sjögren sendromu, lupus eritamatozus gibi otoimmün hastalıklarda, Plummer-Vinson sendromu ve üremik stomatitte angular şelitis gelişir. ${ }^{65,66}$

Klinik olarak asemptomatik olarak gelişebileceği gibi yanma, şiddetli ağrı ve kaşıntı şeklinde bulgular da bulunabilir.

\section{Tanı ve Tedavi}

Hasta hikâyesi ve klinik muayene etkenin belirlenmesi için önemlidir. Oral kavitenin ve alt yüz

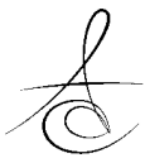


bölgesinin incelenmesi yetersiz oral hijyen, oklüzyon bozuklukları, vertikal boyutu düşük protezlerin varlığı ve deride elastikiyet kaybı gibi lokal faktörleri gösterebilir. Sistemik durum gözden geçirilir. Düşük vertikal boyutlu protezler kullanılıyorsa protezler yenilenir. Ağız hijyeninin önemi anlatılır. Yeni protezlerin kullanılmaya başlanmasına kadar düşük vertikal boyuta bağlı şikâyetin azaltılması için çinkooksit içeren kremler kullanılabilir. Alerji şüphesi bulunması durumunda alerji testi istenir. Ağız kuruluğu için gerekli görülürse tükürük artırıcı ilaçlar verilebilir. Antimikrobiyal tedavi olarak topikal nistatin kremler, neomisin sülfatpolimiksin B sülfat ya da mupirosin merhem kombine olarak iki hafta süre ile kullanılır. Tedavinin başlangıcında yeni bir diş fırçası kullanılmaya başlanmalıdır. Lokal etkenin bulunmadığı veya iki hafta sonunda iyileşmeyen inatçı olgularda altta yatan beslenme ile ilişkili, ilaca bağlı ya da sistemik hastalıklara ait etiyolojinin belirlenmesi için HIV testi, tam kan sayımı, beslenme yetersizliği için testler yapılmalıdır. ${ }^{63-67}$

\section{Mesnetsiz kretler}

Uzun süre protez kullananlarda görülen rezidüel kret rezorpsiyonuyla ilişkili olan mesnetsiz kret, kemiğin hiperplastik dokuyla yer değiştirmesidir. Sıklığı \%729 arasında bildirilmiştir. ${ }^{15}$ Dişsiz hastalarda maksillada \%24 oranında, mandibulada ise \%5 oranında görülür. Özellikle maksillada tam dişsizlik, mandibulada ise dişlerin mevcut olduğu durumda maksiller anterior bölgede, daha nadir olarak da mandibular posterior bölgede görülür. ${ }^{59,68}$ Protezin kullanım süresi ${ }^{9}$ ve kalitesiyle $^{38}$ ilişkili olduğu belirtilmiştir. Mesnetsiz kret ile rezidüel kret rezorpsiyonunun şiddeti arasında ilişki bulunmuştur. ${ }^{59}$

Cerrahi olarak düzeltilebilmekle birlikte, kret son derece azaldığında dikkatli olunmalıdır. Mesnetsiz kret protezde retansiyon problemi oluşturmasına karşın, hiç kret bulunmamasına tercih edilir. ${ }^{59}$

\section{hiperplazi)}

Epulis fissuratum (İnflamatuar fibröz

Epulis fissuratum fibröz konnektif dokunun tümör benzeri hiperplazisi olup, doku uyumu bozuk protez kenarının vestibuler sulkusta oluşturduğu kronik irritasyona bağlı gelişir. ${ }^{69}$ Hareketli protez kullananlarda prevalansı \%1.5-11.4 arasında iken, ${ }^{15}$ total protez kullanan hastalarda \% 29.4 olarak bulunmuştur. ${ }^{5}$ Yaşla artış gösterir. Klinik olarak lezyonlar alveolar vestibulde tek ya da çok sayıda sert ve fibröz hiperplastik doku katlantıları şeklinde görülür. Katlantılar arasında oluşan fissürlerin tabanında inflamasyon ve ülserasyon bulunabilir (Şekil.3). Çoğunlukla labialde gelişmesine karşın, mandibular alveolar kretin lingualinde de görülebilir. Genellikle protez desteği minimal olduğu ve rezopsiyon hızlı olduğu için daha çok mandibulada, sıklıkla anterior bölgede rastlanır. ${ }^{15,70}$ Protezlerin kullanım süresi arttıkça görülme sıklığı da artar..$^{9,13,24,38}$ Rezidüel kret rezorpsiyonuna bağlı olarak protezin stabilitesinin azalması destek dokuda travmaya yol açar. ${ }^{71}$ Erkeklerde kadınlardan daha sık görülmesi, ${ }^{24,71,72}$ erkeklerin protezlerin oluşturduğu yaralanmalara toleransının yüksek olmasına ve kadınlar kadar sık diş hekimine gitme alışkanlıklarının olmamasına bağlanmıştır. ${ }^{72}$

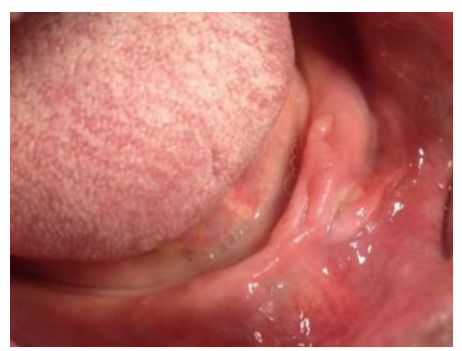

Şekil.3. Total protez kullanan hastada mandibular anterior bölgede vestibuler sulkusta doku katlantıları tarzında görülen epulis fissuratum. Lezyonun katlantıları arasında ülserasyon izlenmektedir.

Diabetes mellitus epulis fissuratum için risk faktörü olarak belirtilmiştir. ${ }^{48}$

Fibroepitelyal polip daha az rastlanan maksiller protezin altında sert damakta oluşan fibröz hiperplazidir. İnce bir sapla damağa tutunan pembe, düz yüzeyli bir lezyondur. Lezyonun kenarları girintili çıkıntılıdır ve yaprak tarzındadır. ${ }^{69}$

Tedavisi cerrahi olarak çıkarılması ve histopatolojik olarak incelenmesinin ardından dokuda travma oluşturan protezin yenilenmesidir.

\section{Travmatik ülserler}

Yeni protezlerin kullanılmaya başlamasından itibaren ilk birkaç gün içinde en sık rastlanan şikâyetlerden biri ağrılı alanlar ve ülserlerdir. Bununla birlikte uzun süredir kullanılan protezlerle de oluşabilir. ${ }^{38}$ Protez kenarlarının uzun olması ve rezidüel alveolar kret rezorpsiyonuyla ilişkili okluzal bozukluklara bağlı gelişebilir. ${ }^{12}$ Protezlerin uyumlanmasından sonra hızla iyileşir. Sıklıkla total protez kullanımı ile ilişkilidir. ${ }^{18}$ Mandibulada \%7 maksillada \%1 oranında görüldüğü belirlenmiştir. ${ }^{68}$

Yaşılıarda, kadınlarda, sigara kullananlarda, gece protezlerini çıkarmayanlarda daha fazla olduğu bildirilmiştir. ${ }^{22,38}$ Eğitim seviyesi ve protezlerin hijyen

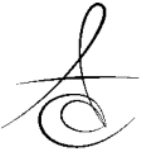


düzeyi arttıkça travmatik ülserlerin görülme sıklığı azalmaktadır. ${ }^{22}$

Beslenme yetersizliği, diabetes mellitus ve kserostomiyi içeren durumlar mukozanın mekanik irritasyona direncini etkileyerek, travmatik ülser oluşumuna yatkın hale getirir. ${ }^{9,33,73} \mathrm{Bu}$ durumda iyileşme daha güçtür ve rekürrens daha sıktır. ${ }^{59}$ Buna ek olarak, diabet oral mukozadaki travmatik ülserlerin iyileşmesini geciktirir. Diabetli hastalarda yara iyileşmesinin geç olması mikroanjiopati, polimorfonükleer lökosit fonksiyonlarında bozulma ile ilişkilendirilmiştir. ${ }^{46}$ Ayrıca konnektif dokuda kolajen sentezindeki azalmayla birlikte, oral epitelin diabetik hastalarda daha ince olduğu ve buna bağlı olarak doku rejenerasyonunun ve hastalık direncinin azaldığı rapor edilmiştir. Kan damarlarının bazal membran kalınlığının artması da dokulara oksijen ve besin iletimini güçleştirir. ${ }^{29,46}$ Beslenme yetersizliği de mukozanın rezistansını baskılayan durumlardan biridir. İlaç kullanımı ve travmatik ülserler arasında ilişki olduğu saptanmıştır. Bu ilişki, ilaçların kserostomik etkilerinden dolayı mukozanın mekanik etkilere daha duyarlı hale gelmesine bağlanmıştır. ${ }^{48}$

Özellikle total protez kullanan yaşlı hastalarda oral karsinomalar (çoğunlukla skuamoz hücreli karsinoma) travmatik ülserler ile karışabileceği için dikkatli olunmalıdır. ${ }^{74}$

Ağrılı alan protezin uyumlanmasından sonra iyileşmiyorsa malignensiden şüphelenilmelidir.

\section{Oral Karsinomlar}

Dokuyla uyumu bozuk olan ya da eskiyen protezlerin oral kanser gelişiminde rol oynadığı düşünülmektedir. Protezin oluşturduğu kronik irritasyonun oral mukozada displazi ve karsinogenezisi uyardığı ileri sürülmüştür. Bu hipotezi kanıtlamak için yapılan çalışmalarda farklı sonuçlar elde edilmiştir. Epidemiyolojik bir çalışmada oral ve orofaringeal skuamoz hücreli karsinom gelişiminde protez kullanımının etkili bir faktör olmadığı bildirilirken, ${ }^{75}$ dokuyla uyumu kötü ve hatalı total protezleri bir risk faktörü olarak tanımlayan çalışmalar da mevcuttur. ${ }^{76-78} \mathrm{Bu}$ nedenle skuamoz hücreli karsinom ya da gingival karsinom gibi travmaya bağlı geliştiği düşünülen malign lezyonların erken teşhisi için hastaların bilinçlendirilmesi ve düzenli kontrollerin yapılması çok önemlidir. ${ }^{79}$

\section{Friksiyonel Keratozis}

Kronik mekanik irritasyona bağlı gelişen, pürüzlü keratotik yüzeyli beyaz lezyondur. Klinik olarak oral prekanseröz lezyonlardan lökoplaki ile benzerlik gösterir. Retromolar alanı ya da dişsiz alveolar kretleri içeren keratozis çiğneme fonksiyonu ya da protezin travmasına bağlı gelişir. Bu tip keratozis travmanın ortadan kalkmasıyla hızla düzelir. Malign transformasyon bildirilmemiştir. ${ }^{69}$

\section{SONUC}

Hareketli protezlere bağlı gelişen oral mukoza lezyonları genel olarak protezlere ait sorunlar, protezlerin kullanım önerilerine uyulmaması ve protezlerin zamanında yenilenmemesi ile ilişkilidir. Sistemik hastalıklar, beslenme yetersizliği ve kserostomi oluşturan ilaçların kullanılması da bu lezyonların gelişimi için risk faktörleridir. Özellikle yaşlı hastalarda risk faktörlerinin daha fazla bulunması düzenli kontrol gereksinimini artırmaktadır. Hareketli protez kullanan hastaların düzenli kontrollerin önemi konusunda bilinçlendirilmesi, hastaların ağız sağığı ile ilişkili yaşam kalitesinin artırımasının yanı sıra, olası malign karakterli lezyonların erken tanısı bakımından da yararlıdır.

Nursel Akkaya: ORCID ID: 0000-0002-2854-1138

Berna Çağırankaya: ORCID ID: 0000-0003-0761-5166

Sema Dural: ORCID ID: 0000-0002-8399-3129

\section{KAYNAKLAR}

1. Zitzmann NU, Hagmann E, Weiger R. What is the prevalence of various types of prosthetic dental restorations in Europe? Clin Oral Implants Res 2007;18 Suppl 3:20-33.

2. Al-Imam H, Özhayat EB, Benetti AR, Pedersen AM, Gotfredsen K. Oral health-related quality of life and complications after treatment with partial removable dental prosthesis. J Oral Rehabil 2016;43:23-30.

3. Saito M, Notani K, Miura $Y$, Kawasaki $T$. Complications and failures in removable partial dentures: a clinical evaluation. J Oral Rehabil 2002;29:627-33.

4. Wagner B, Kern M. Clinical evaluation of removable partial dentures 10 years after insertion: success rates, hygienic problems, and technical failures. Clin Oral Investig 2000;4:74-80.

5. Freitas JB, Gomez RS, De Abreu MH, Ferreira E Ferreira E. Relationship between the use of full dentures and mucosal alterations among elderly Brazilians. J Oral Rehabil 2008;35:370-4.

6. Fleishman R, Peles DB, Pisanti S. Oral mucosal lesions among elderly in Israel. J Dent Res 1985;64:831-6.

7. Ercalik-Yalcinkaya S, Özcan M. Association between oral mucosal lesions and hygiene habits in a

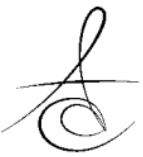


population of removable prosthesis wearers. J Prosthodont 2015;24:271-8.

8. Benso B, Kovalik AC, Jorge JH, Campanha NH. Failures in the rehabilitation treatment with removable partial dentures. Acta Odontol Scand 2013;71:1351-5.

9. Coelho CM, Sousa YT, Daré AM. Denture-related oral mucosal lesions in a Brazilian school of dentistry. J Oral Rehabil 2004;31:135-9.

10. da Silva HF, Martins-Filho PR, Piva MR. Denturerelated oral mucosal lesions among farmers in a semi-arid Northeastern Region of Brazil. Med Oral Patol Oral Cir Bucal 2011;16:740-4.

11. Mikkonen M, Nyyssonen V, Paunio I, Rajala M. Prevalence of oral mucosal lesions associated with wearing removable dentures in Finnish adults. Community Dent Oral Epidemiol 1984;12:191-4.

12. Martori E, Ayuso-Montero R, Martinez-Gomis J, Vinas $M$, Peraire M. Risk factors for denture-related oral mucosal lesions in a geriatric population. J Prosthet Dent 2014;111:273-9.

13. Jainkittivong A, Aneksuk V, Langlais RP. Oral mucosal conditions in elderly dental patients. Oral Dis 2002; 8:218-23.

14. Sönmez NŞ, Gül EB, Nalbant D. Yaşlı hastaların protetik yönden değerlendirilmesi. Atatürk Üniv Diş. Hek Fak Derg 2006; Supp:45-52.

15. MacEntee MI. The prevalence of of edentulism and diseases related to dentures-a literature review. J Oral Rehabil 1985;12: 195-207.

16. Webb BC, Thomas CJ, Willcox MD, Harty DW, Knox KW. Candida-associated denture stomatitis. Aetiology and management: a review. Part 2. Oral diseases caused by Candida species. Aust Dent J 1998;43:160-6.

17. Gendreau L, Loewy ZG. Epidemiology and etiology of denture stomatitis. J Prosthodont 2011;20:25160.

18. Nevalainen MJ, Narhi TO, Ainamo A. Oral mucosal lesions and oral hygiene habits in the home-living elderly. J Oral Rehabil 1997;24:332-7.

19. Barbeau J, Seguin J, Goulet JP, de Koninck L, Avon $\mathrm{SL}$, Lalonde B, Rompré P, Deslauriers N. Reassessing the presence of Candida albicans in denture-related stomatitis. Oral Surg Oral Med Oral Pathol Oral Radiol Endod 2003;95:51-9.

20. Sakki TK, Knuuttila ML, Läärä E, Anttila SS. The association between yeasts and denture stomatitis with behavioral and biologic factors. Oral Surg Oral Med Oral Pathol Oral Radiol Endod 1997;84:624-9.
21. Shulman JD, Rivera-Hidalgo F, Beach MM. Risk factors associated with denture stomatitis in the United States. J Oral Pathol Med 2005;34:340-6.

22. Baran I, Nalçaci R. Self-reported denture hygiene habits and oral tissue conditions of complete denture wearers. Arch Gerontol Geriatr 2009;49:237-41.

23. Petersen $P E$, Yamamoto $T$. Improving the oral health of older people: the approach of the WHO Global Oral Health Programme. Community Dent Oral Epidemiol 2005;33:81-92.

24. MacEntee MI, Glick N, Stolar E. Age, gender, dentures and oral mucosal disorders. Oral Dis 1998;4:32-6.

25. Jeganathan S, Payne JA, Thean HP. Denture stomatitis in an elderly edentulous Asian population. J Oral Rehabil 1997;24:468-72.

26. Pires FR, Santos EB, Bonan PR, De Almeida OP, Lopes MA. Denture stomatitis and salivary Candida in Brazilian edentulous patients. J Oral Rehabil 2002; 29:1115-9.

27. Golecka M, Oldakowska-Jedynak U, MierzwinskaNastalska E, Adamczyk-Sosinska E. Candidaassociated denture stomatitis in patients after immunosuppression therapy. Transplant Proc 2006;38:155-6.

28. Giannini PJ, Shetty KV. Diagnosis and management of oral candidiasis. Otolaryngol Clin N Am 2011; 44: 231-40.

29. Collin HL, Niskanen L, Uusitupa M, Töyry J, Collin $P$, Koivisto AM, Viinamäki $H$, Meurman $J H$. Oral symptoms and signs in elderly patients with type 2 diabetes mellitus. Oral Surg Oral Med Oral Pathol 2000;90:299-305.

30. Ramage G, Tomsett K, Wickes BL, López-Ribot JL, Redding SW. Denture stomatitis: a role for Candida biofilms. Oral Surg Oral Med Oral Pathol Oral Radiol Endod 2004;98:53-9.

31. Yarborough A, Cooper L, Duqum I, Mendonça G, McGraw K, Stoner L. Evidence regarding the treatment of denture stomatitis. J Prosthodont 2016; 25:288-301.

32. Dağistan $\mathrm{S}$, Aktas AE, Caglayan F, Ayyildiz A, Bilge M. Differential diagnosis of denture-induced stomatitis, Candida, and their variations in patients using complete denture: a clinical and mycological study. Mycoses 2009;52:266-71.

33. Dorocka-Bobkowska B, Zozulinska-Ziolkiewicz D, Wierusz-Wysocka B, Hedzelek W, Szumala-Kakol A, Budtz-Jörgensen E. Candida-associated denture

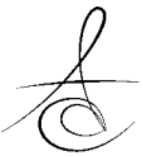


stomatitis in type 2 diabetes mellitus. Diabetes Res Clin Pract 2010;90:81-6.

34. Salerno C, Pascale M, Contaldo M, Esposito V, Busciolano M, Milillo L, Guida A, Petruzzi M, Serpico R. Candida-associated denture stomatitis. Med Oral Patol Oral Cir Bucal 2011;16:139-43.

35. Dahlen G, Blomquist S, Carlen A. A retrospective study on the microbiology in patients with oral complaints and oral mucosal lesions. Oral Dis 2009;15:265-72.

36. Bilhan $H$, Sulun $T$, Erkose G, Kurt $H$, Erturan Z, Kutay O, Bilgin T. The role of Candida albicans hyphae and Lactobacillus in denture-related stomatitis. Clin Oral Investig 2009;13:363-8.

37. Emami E, de Grandmont $P$, Rompre $P H$, Barbeau J, Pan S, Feine JS. Favoring trauma as an etiological factor in denture stomatitis. J Dent Res 2008;87: 440-4.

38. Mandali G1, Sener ID, Turker SB, Ulgen H. Factors affecting the distribution and prevalence of oral mucosal lesions in complete denture wearers. Gerodontology 2011;28:97-103.

39. Figueiral MH, Azul A, Pinto E, Fonseca PA; Branco $F M$, Scully C. Denture-related stomatitis: identification of aetiological and predisposing factors - a large cohort. J Oral Rehabil 2007:34;448-55.

40. Gasparoto TH, Vieira NA, Porto VC, Campanelli AP, Lara VS. Ageing exacerbates damage of systemic and salivary neutrophils from patients presenting Candida-related denture stomatitis. Immun Ageing 2009;6:3.

41. Kovac-Kavcic M, Skaleric U. The prevalence of oral mucosal lesions in a population in Ljubljana, Slovenia. J Oral Pathol Med 2000;28:331-5.

42. Dutt $P$, Chaudhary SR, Kumar P. Oral health and menopause: a Comprehensive review on current knowledge and associated dental management. Ann Medical Health Sci Res 2013;3:320-3.

43. Valimaa $H$, Savolainen $S$, Soukka $T$, Silvoniemi $P$, Makela S, Kujari H, Gustafsson JA, Laine M. Estrogen receptor-beta is the predominant estrogen receptor subtype in human oral epithelium and salivary glands. J Endocrinol 2004;180:55-62.

44. Webb BC, Thomas CJ, Willcox MD, Harty DW, Knox KW. Candida-associated denture stomatitis. Aetiology and management: a review. Part 1. Factors influencing distribution of candida species in the oral cavity. Aust Dent J 1998;43:45-50.

45. Aly FZ, Blackwell CC, MacKenzie DA, Weir DM. Identification of oral yeast species isolated from individuals with diabetes mellitus. Mycoses 1995;38:107-10.

46. Guggenheimer J, Moore PA, Rossie K, Myers D, Mongelluzzo MB, Block HM, Weyant R, Orchard T. Insulin-dependent diabetes mellitus and oral soft tissue pathologies. I. Prevalence and characteristics of non-candidal lesions. Oral Surg Oral Med Oral Pathol Oral Radiol Endod 2000;89:563-9.

47. Kadir T, Pisiriciler R, Akyüz S, Yarat A, Emekli N, Ipbüker A. Mycological and cytological examination of oral candidal carriage in diabetic patients and non-diabetic control subjects: thorough analysis of local aetiologic and systemic factors. J Oral Rehabil 2002;29:452-7.

48. Dundar N, Ilhan Kal B. Oral mucosal conditions and risk factors among elderly in a Turkish school of dentistry. Gerontology 2007;53:165-72.

49. Daniluk T, Tokajuk G, Stokowska W, Fiedoruk K, Sciepuk M,Zaremba ML, Rozkiewicz D,CylwikRokicka D,Kedra BA,Anielska I,Gorska M, Kedra BR. Occurrence rate of oral Candida albicans in denture wearer patients. Adv Med Sci 2006;51:77-80.

50. Samaranayake LP, MacFarlane TW. A retrospective study of patients with recurrent chronic atrophic candidosis. Oral Surg Oral Med Oral Pathol 1981;52:150-3.

51. Paillaud E, Merlier I, Dupeyron C, Scherman E, Poupon J, Bories PN. Oral candidiasis and nutritional deficiencies in elderly hospitalised patients. Br J Nutr 2004;92:861-7.

52. Dorocka-Bobkowska B, Budtz-Jörgensen E, Wloch S. Noninsulin-dependent diabetes mellitus as a risk factor for denture stomatitis. J Oral Pathol Med 1996;25:411-5.

53. Kulak-Ozkan Y, Kazazoglu E, Arikan A. Oral hygiene habits, denture cleanliness, presence of yeasts, and stomatitis in elderly people. J Oral Rehabil 2002;29:300-4.

54. Divaris K, Ntounis A, Marinis A, Polyzois G, Polychronopoulou A. Loss of natural dentition: multi-level effects among a geriatric population. Gerodontology 2012;29:92-9.

55. Peltola P, Vehkalahti MM, Wuolijoki-Saaristo K. Oral health and treatment needs of the long-term hospitalised elderly. Gerodontology 2004;21:93-9.

56. Marchini L, Tamashiro E, Nascimento DF, Cunha VP. Self-reported denture hygiene of a sample of edentulous attendees at a University dental clinic and the relationship to the condition of the oral tissues. Gerodontology 2004;21:226-8.

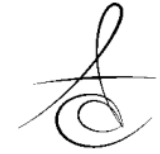


57. de Almeida AL, Catalani DT, Garcia de Oliveira PC, Soares S, Tunes FS, Neppelenbroek KH. Assessment of periodontal and hygiene conditions of removable partial dentures in individuals with clefts. Cleft Palate Craniofac J 2016;53:727-31.

58. Kossioni AE. The prevalence of denture stomatitis and its predisposing conditions in an older Greek population. Gerodontology 2011;28:85-90.

59. Carlsson GE. Clinical morbidity and sequelae of treatment with complete dentures. J Prosthet Dent 1997;79:17-23.

60. Felton D, Cooper L, Duqum I, Minsley G, Guckes A, Haug S, Meredith P, Solie C, Avery D, Deal Chandler N; American College of Prosthodontists. Evidence-based guidelines for the care and maintenance of complete dentures: a publication of the American College of Prosthodontists. J Prosthodont 2011;20 Suppl 1:S1-S12.

61. Salonen MA, Raustia AM, Oikarinen KS. Effect of treatment of palatal inflammatory papillary hyperplasia with local and systematic antifungal agents accompanied by renewal of complete dentures. Acta Odontol Scand 1996;54:87-91.

62. Altarawneh S,Bencharit S, Mendoza L, Curran A, Barrow D, Barros S, Preisser J, Loewy ZG, Gendreau $L$, Offenbacher $S$. Clinical and histological findings of denture stomatitis as related to intraoral colonization patterns of Candida albicans salivary flow and dry mouth. J Prosthod 2013;22:13-22.

63. Park KK, Brodell RT, Helms SE. Angular cheilitis, part 1: local etiologies. Cutis 2011;87:289-95.

64. Sharon V, Fazel N. Oral candidiasis and angular cheilitis. Dermatol Ther 2010;23:230-42.

65. Farah CS1, Lynch N, McCullough MJ. Oral fungal infections: an update for the general practitioner. Aust Dent J 2010 ;55 Suppl 1:48-54.

66. Park KK, Brodell RT, Helms SE. Angular cheilitis, part 2: nutritional, systemic and drug-related causes and treatment. Cutis 2011;88:27-32.

67. Stoopler ET, Nadeau C, Sollecito TP. How do I manage a patient with angular cheilitis? J Can Dent Assoc 2013;79:d68.

68. Xie Q, Närhi TO, Nevalainen JM, Wolf J, Ainamo A. Oral status and prosthetic factors related to residual ridge resorption in elderly subjects. Acta Odontol Scand 1997;55:306-13.

69. Neville BW, Damm DD, Allen CM, Bouquot JE. Erythematous candiasis. In: Oral and Maxillofacial Pathology. 3rd ed. St.Louis:Saunders Elsevier; 2009. p. 214, 216-217.
70. Canger EM, Celenk P, Kayipmaz S. Denture-related hyperplasia: a clinical study of a Turkish population group. Braz Dent J 2009;20:243-8.

71. Coelho CM, Zucoloto S, Lopes RA. Denture-induced fibrous inflammatory hyperplasia: a retrospective study in a school of dentistry. Int J Prosthodont 2000;13:148-51.

72. Jainkittivong A, Aneksuk V, Langlais RP. Oral mucosal lesions in denture wearers. Gerodontology 2010;27:26-32.

73. Talacko AA, Gordon AK, Aldred MJ. The patient with recurrent oral ulceration. Aust Dent J 2010;55 Suppl 1:14-22.

74. Valente VB, Takamiya AS, Ferreira LL, Felipini RC, Biasoli ÉR, Miyahara GI, Bernabé DG. Oral squamous cell carcinoma misdiagnosed as a denture-related traumatic ulcer. A clinical report. J Prosthet Dent 2016;115:259-62.

75. Lissowska J, Pilarska A, Pilarski P, SamolczykWanyura D, Piekarczyk J, Bardin-Mikolłajczak A, Zatonski W, Herrero R, Munoz N, Franceschi S. Smoking, alcohol, diet, dentition and sexual practices in the epidemiology of oral cancer in Poland. Eur J Cancer Prev 2003;12:25-33.

76. Velly AM, Franco EL, Schlecht N, Pintos J, Kowalski LP, Oliveira BV, Curado MP. Relationship between dental factors and risk of upper aerodigestive tract cancer. Oral Oncol 1998;34:284-91.

77. Rosenquist K. Risk factors in oral and oropharyngeal squamous cell carcinoma: a population-based case-control study in southern Sweden. Swed Dent J Suppl 2005;179:1-66.

78. Rosenquist K, Wennerberg J, Schildt EB, Bladström A, Göran Hansson B, Andersson G. Oral status, oral infections and some lifestyle factors as risk factors for oral and oropharyngeal squamous cell carcinoma. A population-based case-control study in southern Sweden. Acta Otolaryngol 2005;125: 1327-36.

79. Bulut E, Yılmaz F, Bekçioğlu B, Günhan Ö. Posterior alveolar krette dişeti yerleşimli skuamoz hücreli karsinoma: olgu sunumu. Atatürk Üniv Diş Hek Fak Derg 2013; 23:239-43.

\section{Yazışma Adresi}

Nursel Akkaya

Hacettepe Üniv Diş HekFak Ağız, Diş ve Çene

Radyolojisi A.D. Sihhiye/Ankara/Türkiye, 06100

Tel: +903123052719

Faks: +903123091826

E-mail: ynursel@hacettepe.edu.tr 